\title{
Victorian maternal child health nurses' knowledge, attitudes and beliefs towards national registration changes
}

\author{
Rayleen Breach, Linda K. Jones* \\ Discipline of Nursing and Midwifery, School of Health Sciences, RMIT University, Victoria, Australia
}

Received: January 4, 2017

Accepted: March 14, 2017

Online Published: March 27, 2017

DOI: $10.5430 /$ jha.v6n3p1

URL: https://doi.org/10.5430/jha.v6n3p1

\begin{abstract}
In 2010 National Registration for nurses was established which was likely to impact the role of the maternal and child health nurses $(\mathrm{MCH})$ in Victoria. This study explored the perceived impact of the national changes to the $\mathrm{MCH}$ nurse workforce in Victoria following the implementation of national registration and a proposed national service framework. A qualitative exploratory descriptive design was employed with the purpose of exploring the knowledge, attitudes and beliefs of Key Stakeholders (KSH) to the recent changes and perceived impact to Victorian $\mathrm{MCH}$ nurses. The significance of this study lies with understanding the gaps in current knowledge of KSH to the national changes. Outlined briefly in this paper will be main findings from the KSH. This involved interviewing $12 \mathrm{KSH}$ from management positions, including Local Government Coordinators, Policy Advisors to the Department of Education and Early Childhood Development, the Municipal Association of Victoria, along with academics from Universities that provide postgraduate Child and Family Health education programs for the $\mathrm{MCH}$ nurse qualification. Date was transcribed verbatim and content analysis used. Categories were developed by identifying recurrent patterns from the data, labels were then chosen which reflected the participant's words: "common standard"; "losing our identity"; "universal service"; "we do it well" and "imposed from above". Overall the KSH were concerned how the disparity in education and qualifications would be resolved and the effect this would have on the service. Findings from this study highlight the importance of comprehensively investigating services offered by all jurisdictions and using collaboration, communication and leadership to effectively introduce change.
\end{abstract}

Key Words: Maternal \& child health nursing, Victoria, National registration, Change, Impact, Maternal \& child health service

\section{INTRODUCTION}

Prior to the reforms in national registration in Australia, there were 8 jurisdictions each having their own, different registration requirements for health professionals. In order to ensure the health workforce was able to respond to the evolving care needs of Australians while maintaining quality and safety of health services, and facilitate workforce mobility, the Council of Australian Government undertook workforce planning. ${ }^{[1]}$ Reforming national registration was high on the agenda as a consequence of the disparity is registration requirements across Australia. The reform resulted in the formation of a national registration scheme for health professionals in July $2010{ }^{[2]}$ This resulted in all health professionals, including nurses and midwives, being registered under one organization called the Australian Health Practitioners Regulation

\footnotetext{
*Correspondence: Linda K. Jones; Email: 1.jones@federation.edu.au; Address: Discipline of Nursing and Midwifery, School of Health Sciences, RMIT University, Victoria, Australia.
} 
Agency (AHPRA). Under this organization, each health professional group would have their own board through which they would be registered. As a consequence of this national reform approach, there was a need to undertake significant changes in a number of areas within each jurisdiction. This included the areas of professional practice, policy, governance, programs and service delivery, especially so for maternal and child health $(\mathrm{MCH})$ nurses. ${ }^{[3]}$

In relation to the area of service delivery in $\mathrm{MCH}$, the draft report by the Allen Consulting Report for a National Framework for Universal Child and Family Health Services was released in 2009. This report was commissioned by the Child Health and Wellbeing Subcommittee of the Australian Population Health and Development Principal Committee of the Australian Health Ministers' Advisory Council in 2008 to develop a draft national framework for child and family health services. The Allen report proposed a national framework that would reduce the reported disparities between states and territories in some areas of service delivery and assist in the delivery of services while maintaining national standards across all jurisdictions. ${ }^{[4]}$ There was a belief amongst the Victorian $\mathrm{MCH}$ nurses that a significant change of this proportion could have the potential to substantially change the current role of the MCH service in Victoria. ${ }^{[5]}$ Despite this belief, no research has been undertaken to assess the impact of these national changes on the $\mathrm{MCH}$ nurses in Victoria. This research aimed to investigate the impact of these changes on the MCH Key Stakeholders (KSH) to address this deficit.

Victorian MCH nurses are qualified as General Nurses and Midwives, and have attained a Post Graduate Diploma or Master's degree in Child and Family Health Nursing. Other jurisdictions do not have the requirement for both nursing and midwifery or a postgraduate program. ${ }^{[6]} \mathrm{MCH}$ nurses visit $95 \%$ to $98 \%$ of all Victorian mothers with newborns at home within two weeks following discharge from hospital. ${ }^{[7]}$ Engagement rates in other jurisdictions are not quite as high due to the family needing to initiate first contact whereas Victoria has a direct birth notification system to the service. ${ }^{[4]}$ The role of the MCH nurse is to provide universal primary healthcare service, which includes assessment and support to mothers and their family, up to the age the child commences kindergarten. This service includes early detection and intervention, and health promotion education. $\mathrm{MCH}$ nurses are employed through the local government authorities (LGA) directly under the Department of Education and Early Childhood Development (DEECD). This Department is accountable for the planning and providing of early childhood services in partnership with local government. It is well documented in the literature that the early years provide the foundation for lifelong physical, social and emotional wellbeing. ${ }^{[8]}$ The $\mathrm{MCH}$ nurses in Victoria are uniquely placed to influence these critical periods in a child's life by promoting consistency of services. $\mathrm{MCH}$ nurses are internationally recognised, highly skilled independent specialist nurses who take a holistic approach to health care along with being at the forefront of Early Childhood service in the community. ${ }^{[9,10]}$

\section{Methods}

The aim of this study was to explore the knowledge, attitudes and beliefs of the MCH nurses in Victoria to the perceived impact of national changes to registration and service provision. Interviews were undertaken with $12 \mathrm{KSH}$ who have been working either in management, academia or service coordination from different influencing positions for example; DEECD, LGA or Coordinators of Family and Children's Services from local government areas across Victoria. Interviews were also undertaken with $\mathrm{MCH}$ nurses but the results of these are not within the scope of this paper. As there was little known about this area of research, a qualitative exploratory descriptive research methodology was employed to undertake the research. ${ }^{[1,12]}$ In addition, the data would be too complex to enable it to be captured quantitatively. ${ }^{[11,13]}$

\subsection{Recruitment and sample size}

Purposive sampling technique was used, with recruitment occurring through advertising in the Victorian Association of Maternal and Child Health Nurses journal and at DEECD state conferences. Potential participants expressed interest by contacting the researcher to organise a convenient time and place to be interviewed. This recruitment continued until no new data emerged and saturation was achieved. ${ }^{[11]}$

\subsection{Data collection}

Interviews were approximately 45 minutes long and were audio recorded to ensure rigor. The semi structured interviews comprised of questions related to national registration, including qualifications and registration requirement, service provision and framework, and change. Each category consisted of five to six questions, and included questions such as "what is your understanding of national registration?" and "what impact do you think national registration will have on $\mathrm{MCH}$ service in Victoria?"

Following the interviews, data were transcribed verbatim and then read through and checked with the recordings to ensure accuracy. To ensure reliability of analysis the researcher and supervisor read through the transcripts for the process of coding the data. ${ }^{[12]}$ Content analysis using the steps identified by Dey ${ }^{[14]}$ occurred through a process of reading and identifying categories from the transcripts. ${ }^{[15]}$ In order to limit 
the richness of the data being lost, distorted or fragmented, a systematic and rigorous analysis process using NVIVO was undertaken. ${ }^{[16,17]}$

\subsection{Ethical considerations}

Ethics approval was granted from Royal Melbourne Institute of Technology University's Human Research Ethics Committee and DEECD. Participants were given a plain language statement and then consented to be interviewed prior to commencing the audio recording. In order to ensure confidentiality and anonymity, transcripts were deidentified by using numbers as identifiers.

\section{RESUlTS}

Participants ranged in age of 46 to 55 years, and had nursing experience ranging from 1 to 20 years, with the majority having more than 10 years of experience. This experience was in upper management, higher service delivery and education. Qualifications of the KSH ranged from Graduate Diploma to Masters with four holding additional Masters of Business Management degrees.

Categories were developed by identifying recurrent patterns from the data and organised into groups through a process of inductive reasoning. Category labels were defined that reflected the participants own words: "Common standard", "Losing our identity", "Universal service", "We do it well" and "Imposed from above". Significant findings only are presented here from these categories.

\subsection{Common standard}

National registration or the notion of having one registration across all jurisdictions in Australia as opposed to eight separate registrations was seen by the majority of $\mathrm{KSH}$ to be of benefit. This is because it provided a "common standard" for health professionals and a reduction in the bureaucratic process of registration. In other words:

“... standardised nurse registration in Australia... ” $\mathrm{KSH}$ 12 .

One of the advantages of having national registration highlighted by the $\mathrm{KSH}$ was the ability of health professionals to work in different jurisdictions without the requirement of separate registrations for each. This was particularly an issue for $\mathrm{MCH}$ nurses who practice in border towns. As one participant commented, national registration therefore assisted with:

“... minimising of border to border discrepancies and difficulties..." KSH6

Despite the understood advantages for the ease of movement between jurisdictions, the majority of participants stated that they would not relocate to another jurisdiction. The reasons for this varied from:

“... I like the way we practice here... ” KSH4.

A key reason why KSH would not move was the significant concern they voiced, which was the disparity between the qualifications and practice standards among jurisdictions. There was a strong belief expressed among the participants that Victorian $\mathrm{MCH}$ nurses were perceived to be more highly qualified and provided a more comprehensive service than in other jurisdictions;

“... I work in the service that best meets my requirements... I have the best qualifications... I don't think it would be a positive move" KSH 8.

The impact of the disparity and why the Victorian KSH were so concerned is expressed in the following:

"I am quite concerned because the qualifications in Victoria are different... we have midwifery ... the other states don't have to have midwifery..." KSH9.

This reflected the essence of the concerns expressed by KSH regarding the impact of national registration, and in itself the rationale behind it. The difference previously was the different registration requirements between jurisdictions. This disparity then became about qualifications. Many KSH could appreciate the rationale behind the changes but were also realistic about the potential impact:

“... while there are some advantages... it has raised a lot of disadvantages not the least the impact on MCHN in Victoria... " KSH8.

The KSH believed that there had not been a thorough enough examination of the options and that the system behind the national changes failed to identify the ramifications prior to implementation:

"I think unfortunately when you introduce a major change you really need to make sure the system behind it works... sadly that appears to have fallen down..." KSHI.

\subsection{Losing our identity}

One of the consequences of national registration for $\mathrm{MCH}$ nurses was that they lost their notation of $\mathrm{MCH}$ nurse and recognition of midwifery as an additional qualification on their registration certificate. This occurred because Victoria was the only jurisdiction that had this notation and requirement to be a registered nurse and midwife. The issue here is that the MCH nurses believed the notation on their registration supported the level of service they provided in Victoria. This study captured participants at a vulnerable time when many were questioning their value, worth and employability 
following the loss of acknowledgement of their speciality:

"I think it is the saddest thing out... this is a specialty area of nursing ... to remove recognition of the qualification means lowering the standard and opens up the gates for lesser qualified... ” KSH8.

The implication expressed here by the participants was that people from other jurisdictions seeking employment in Victoria who did not have the same qualifications or scope of practice could impact greatly on what is perceived to be a highly successful service. One of the major issues, furthermore, was the Productivity Commission's draft findings from the review of the Early Childhood Development Workforce indicated that there was little evidence to suggest that a midwifery qualification was required. ${ }^{[18]}$

It was clear from the data that the KSH strongly disagreed with this draft report and supported the need for midwifery qualifications as an integral part of the service they provide. The KSH believed the loss of the midwifery qualification would be to the detriment of the service and families because:

“... we see them soon after birth... you cannot have the same understanding without midwifery... it gives you the skills and knowledge to deal with post birth problems of the mother... you never know what is going to walk through your door. . " KSH 6.

The KSH unanimously agreed that the experience gained from having the midwifery qualification gave them added advantages with offering complex care following traumatic births:

"Maternal \& Child Health is an extension of midwifery.. you need the delivery, antenatal and postnatal knowledge... it's not just physical it's all the psychological factors you take in... the family and social issues... " KSH 11.

On the other hand, there were KSH who indicated that midwifery qualifications itself may not be necessary. Instead the MCH course would need to have a compilation of midwifery components to enable the course to bridge the gap of knowledge required to effectively care for mothers. These further emphases the necessity for midwifery education of sorts. The problem was, however:

“... we really need some compelling evidence as to why we need to be midwives... currently there is not enough research going on" KSHI.

\subsection{Universal service}

Service provision across Australia was different in each jurisdiction as a consequence of the qualification and registration requirements being different. With national registration, there was a need for a national service framework to be developed to complement the uniform qualifications. The majority of $\mathrm{KSH}$ indicated that the development of a national service framework was in principle a necessary change to provide universal child and family health services. A number of $\mathrm{KSH}$ were confused as to what this framework would constitute considering the current diversity that existed between jurisdictions and could not see how this could be implemented. There was agreement in principle:

“... from an idealistic view point... a national framework with care would be fantastic ... to have standardised care across Australia is a really good idea ..." KSH 8 In contrast to the number of KSH that had an understanding of a national framework, there were some KSH that openly stated they had limited understanding. When asked for their understanding of the national framework, they replied; "... not good..." KSH 9 or "I have limited understanding..." KSH6.

For these KSH who did understand a national framework it was obvious from the data that they believed there were a number of important aspects to be considered for inclusion in the national framework to ensure a quality service, with appropriately qualified staff:

“... an evidence-based practice framework ... a minimum standard... strength based with a minimum grad dip... nurses equipped to deal with mental health issues, anxiety and substance abuse... we shouldn't go back to Stone Age apprenticeship style training either.. ” KSH 2.

Additionally, the KSH believed that there had not been enough communication to give clarity to what was actually being explored for the framework and this in fact led to much of the confusion. This was further compounded by the fact that there was a perception that this was more of a political issue driven by a few which consequently added to the confusion:

“... from a confusion point of view... there is not enough clarity with what they are actually looking at in the framework that is federally driven... a lot of people with their fingers in many pies... that confuses practitioners because they don't know who's driving what or for what reason... it's too political at the moment..." KSH 8.

The majority of KSH believed that the transition to a national framework in principle was a positive move for the families of Australia. They were, however, concerned for the continuance of the service at its present level:

"I think it's a huge opportunity to improve services across Australia, but my fear is that the opportunity will be taken 
to reduce services and that the quality of services will suffer because of funding” KSH3.

\subsection{We do it well}

Despite the lack of clarity and confusion around the development of the national framework, the perception was that Victoria had a clear service framework for $\mathrm{MCH}$. The majority of the KSH indicated they believed the Victorian framework was operating very successfully and should be considered in principal for a national service framework. One of the reasons why the Victorian service was identified by the KSH as being worthy of consideration for benchmarking the national framework was the strong evidence based philosophy behind it:

“... the service has been researched considerably over the last decade with strong evidence to base it on... ” KSHIO.

One participant stated, however, that while comprehensive, the Victorian model may in fact not transpire to a national workable framework:

“... the Victorian model is a very comprehensive and successful ... it offers families so much more than any other state but nationally... I don't know if that can work... " KSH6.

In addition, the reasons identified by the KSH believed the Victorian service to be the best was because Victoria is supported by state and local governments with infrastructure, legislated birth notifications and independent funding. For the participants this meant the service was streamlined therefore:

“... the service can operate at a level which is excellent rather than good..." KSH 10.

The KSH, furthermore, believed the Victoria service was strengthened by the education pathways for $\mathrm{MCH}$ nurses to practice and the fact that Victoria had a history of:

“... the strongest evidence-based practise... ” KSH8.

Despite the fact the KSH believed the service in Victoria was of a high standard, they were also realistic about other jurisdictions having value as well on the national platform.

“... we need to look at what other jurisdictions can bring to the table..." KSH 12.

The majority of KSH felt the transition to a national framework in principle was a positive move for the families of Australia. A number of KSH, however, indicated they had concerns for the continuance of the service at its present level:

“... I think it's a huge opportunity to improve services across Australia, but my fear is that the opportunity will be taken to reduce services and that the quality of services will suffer because of funding... " KSH3.

The following comment from another KSH supports the fears articulated by many regarding the possible direction of the service as clearly stated below:

"... I am terrified that we are going to the lowest common denominator and the cheapest options. . . absolutely devastated if that happens..." KSH5.

Another contributing factor for the KSH was the fact that the significance of the national changes and the impact to the Victorian MCH nurses had yet to be fully realized by the governing authorities and the $\mathrm{MCH}$ nurses themselves.

“... I don't think people appreciated the depth of what was being proposed..." KSH 1.

\subsection{Imposed from above}

As previously identified the KSH knowledge and understanding offered surprising results in the number of stakeholders who had limited knowledge compared to stakeholders who had a more comprehensive understanding regarding what a national framework should consist of. From the data a number of issues were identified that may have contributed to this. One of these being a key concern related to the lack of involvement and communication with the KSH in Victoria regarding the changes at the national level:

“... something that is imposed from above is not going to work... it has to come from the bottom up as well as from the top down... " KSH 12.

There was a strong belief amongst the KSH that this in fact was what had been happening. In addition, the KSH alleged that decisions regarding the national service were being made by policy makers with limited understanding of what the Victorian service entailed. The reason this was perceived an issue was because:

“... policy people bring one set of glasses when they are looking at things ... they just don't seem to know what the grassroots stuff is all about..." KSH12.

From the data it was apparent that the KSH believed decisions regarding the service were being made without thorough investigation of the implications of the change:

“... decisions are made when there isn't anybody around with a practical view of what's happening on the ground... unless you incorporate their point of view you are always going to have to drag them along..." KSH3.

The KSH further believed that being involving in the consultation proceedings was integral to the success of the change 
process:

“... it needs to be relevant for people to feel that they own it... come to the table with goodwill... be prepared to give and take... we have an excellent service in Victoria but we could learn from the others with things they do well... " KSH 12.

\section{Discussion}

A common standard for health professionals across Australia was supported in principal by the majority of KSH following the change to national registration. While Council of Australian Government (COAG) was attempting to offer consistency between jurisdictions and remove the disparity, it appeared to the KSH to be creating more inequality, especially regarding qualifications. This disparity in qualifications and education had been identified by both $\mathrm{COAG}^{[18]}$ and Kruske and Grant. ${ }^{[6]}$ Similar disparity issues had been experienced by the psychiatric nurses in Victoria with the introduction of the Nurses Act in 1993. Prior to this, there was a Bachelor of Psychiatric nursing leading to a separate register. Mental health then became part of a comprehensive nursing degree and various postgraduate programs. The problem was, however, that these programs did not necessarily increase the mental health content. The overall result was a disparity of qualifications and education in the mental health field. ${ }^{[19,20]}$

There were a number of concerns expressed by the $\mathrm{KSH}$ regarding the loss of notation of $\mathrm{MCH}$ nurses' qualification on the register. One of these concerns was, however, that the loss of notation may have been in reality part of the process to decrease the disparity in registration requirements across Australia. This is because Victoria was the only jurisdiction that had the requirement of both $\mathrm{MCH}$ and midwifery qualification to practice. The majority of $\mathrm{KSH}$ believed that the midwifery qualification was fundamental to the unique service they provided and that the Victorian service was in fact different to what other jurisdictions provided, and this was why midwifery was essential. At first glance the benefits of national registration appeared to be self-evident, however, it was not until after national registration was implemented that the reality of the implications from the disparity of qualifications and education levels became apparent. This was seen to make the development of the service framework more of an issue due to disparities not being addressed prior to the implementation of national registration. Similar issues were experienced by the mental health nurses when they lost their separate registration and degree. ${ }^{[19]}$ In principle, comprehensive registration was a good idea but in practice this resulted in workforce shortfall. The result, as identified by Happell ${ }^{[19]}$ was a profession in crisis. Postgraduate programs for mental health nursing were developed as a consequence although the structure varied between the jurisdictions and therefore the disparity continued. ${ }^{[21]}$

Both the loss of notation and the adamant belief from this group of $\mathrm{KSH}$ expressed to retain midwifery, has a substantial implication to the sustainability of the workforce. The implication being that to become a $\mathrm{MCH}$ nurse in Victoria requires extensive education which would take some time to achieve in addition to needing to maintain the necessary professional development ongoing registration requirements. This is not only about the time it takes to become a qualified practitioner but also the money needed to achieve that. There is no doubt that this issue needs to be explored further. If $\mathrm{MCH}$ is viewed as an extension of midwifery, then the midwifery qualification is more important than a nursing qualification. Maybe then $\mathrm{MCH}$ nurses do not need to undertake a nursing degree as well. Obviously this would require an evaluation of the content of the midwifery and maternal child health curriculums and what would be required to make up the difference. The $\mathrm{MCH}$ program curriculum would then need to expand to include the necessary cross disciplinary knowledge. The KSH level of understanding of the national framework was surprisingly limited. This was partly explained by the $\mathrm{KSH}$ as being due to the limited information disseminated regarding the framework through the $\mathrm{MCH}$ nurse network. The $\mathrm{KSH}$ further suggested that developing such a framework collaboratively with the practitioners that provided the service, would in fact achieve a more cohesive and successful implementation with less resistance to change. In addition to this the KSH believed that developing the national framework first before national registration was implemented may have benefited the process of the change to a national platform. This study suggested there is a need to comprehensively investigate the services offered by all the jurisdictions before commencing the development of a national framework. A national study is currently being undertaken [CHoRUS study] examining the feasibility of a national approach to child and family health that aims to address this deficit. ${ }^{[22]}$

The fact that this group of $\mathrm{MCH}$ nurse had such a strong belief that the Victorian service framework should be used as the benchmark for the national framework made them appear insular and ignorant of the other professional jurisdictions across Australia. This could be referred as having territorial traits as they strongly defended what they perceived was the best service provided despite not being fully aware of what other jurisdictions do. There is a possible explanation for this perceived territorial traits by some as indicated by the early works of Reiger \& Kelleher, ${ }^{[23]}$ with their study. Reiger $\&$ Kelleher ${ }^{[23]}$ indicated that the Victorian MCH nurses traditionally shared a strong sense of identity as independent 
professional practitioners. This started following the commencement of Compulsory Competitive Tendering (CCT) during the early 1990s, when the Coordination of the service and, in part the MCH nurses, became more developed. This tendering process was part of the municipal restructuring and opened up the possibilities for other organisations, apart from the current MAV, to coordinate the services instead. ${ }^{[23]}$ Basically MCH nurses had to reapply for their positions and account for what they did and how they spent their time. ${ }^{[2]}$ This then directly challenged traditional notions of MCH nurses' identity and practice that were based on claims to professional autonomy. Throughout these changes, the traditional role of $\mathrm{MCH}$ was beginning to change with demarcation of roles causing anxiety and fear which lead to a defensive climate even though professional identity, vision and commitment remained strong. ${ }^{[23]}$ The CCT was abolished in 1999. The consequence of the CCT was that the $\mathrm{MCH}$ nurses became more accountable but at the same time became very territorial, not wanting to lose their autonomy or identity.

Despite the fact the Victorian KSH believed they had a superior service, they in fact had limited knowledge of services offered by the other jurisdictions. An interesting point to make here, therefore, is that these participants believed that they provided the best service which should then be used as a benchmark to develop the national service, when they were mostly unaware of what was offered elsewhere. It was however, not surprising that they did not know how services were provided elsewhere in Australia. Keeping informed is difficult unless one belongs to the professional organisation which helps keep people informed through the network this creates. This is part of being a professional. ${ }^{[25]}$ Interestingly though the KSH group should have been more aware of what services were provided elsewhere as this was part of their role as managers to know. This was found in this study to be not necessarily so. This all leads to the fact that there were some KSH that do not necessarily see themselves as being professionals. In other words, these KSH were more focused on the task at hand and the job rather than being aware of the bigger picture of their profession. ${ }^{[24]}$ A professional views work as being central to their life which in turn becomes their life, as they make a commitment to the subculture of that work. In order to embrace professionalism would mean that the KSH would be less insular and instead be aware of what occurs in other jurisdictions and have more of a national focus.

For the majority of KSH in this study the issue was, however, more about how the change was implemented and the lack of consultation and inclusion in the processes of change. Given a more encompassing process, the KSH may well have been

Published by Sciedu Press more accepting of the change. While the majority of KSH were not against change, they believed it was more about the process of change, how the change was introduced and that it appeared to be more top down instead of inclusive. There needed to be more communication and a strong leadership group driving the changes collaboratively with the $\mathrm{MCH}$ nurses. A process of organisational change was not followed, resulting in frustration and a lack of confidence in the national agenda.

\section{Limitations}

While acknowledging that professional claims are often the result of collective action, the analysis presented here reports evidence of individual KSH perceptions of the impact from the national change to registration and services provision. The limitation of this research was that the research was situated only in Victoria, and the fact that this paper does not include the MCH nurses who may hold different views.

\section{Conclusion}

This article offers an insight into the knowledge, attitudes and beliefs of the KSH, to the perceived impact of the national changes to registration and service provision in Victoria. The findings indicate that the KSH believed the loss of the notation of the MCH nurse qualification appeared to have caused a considerable amount of concern to all participants interviewed. Whether removing this notation was an attempt to ameliorate the disparity is not clear. What became evident was, however, that this disparity in qualifications and education made any development of a national service framework difficult. In regards to the national framework, there was limited knowledge regarding what this would constitute. Likewise, there was agreement that the framework from Victoria could be a significant benchmark for consideration for the national framework to be based on.

Knowledge derived from this study emphasises the need for additional consultation and communication on the development of a service framework to be facilitated at all levels. It is recommended that further investment in collaborative research on child health services be attended by all jurisdictions to inform future policy development. In addition, it is further recommended that representation of KSH from Victoria and significant peak professional bodies are included in any further review of the development of the national service framework.

\section{ACKNOWLEDGeMENTS}

This work is part of a Doctoral research undertaken through RMIT. A note of appreciation goes to the participants for their time. Funding was received through the School of Grad- 
uate Research and the School of Health Sciences at RMIT. this research.

A postgraduate scholarship was awarded from the Victorian Association of Maternal Child Health Nurses in support of

\section{CONFLicts OF InTEREST Disclosure}

The authors declare they have no conflict of interest.

\section{REFERENCES}

[1] Council of Australian Government. Communique July. Commonwealth of Australia Publishing. 2006. Available from: http: www .ar chive.coag.gov.au/coag_meeting_outcomes

[2] Australian Health Practitioner Regulation Authority. About AHPRA Who We Are. Retrieved 20th May, 2013. Available from: http: //www . ahpra.gov. au/About-AHPRA . aspx

[3] Schmied V, Donovan J, Kruske S, et al. Commonalities and challenges: a review of Australian state and territory maternity and child health policies. Contemporary Nurse. 2011; 40(1): 106-117. PMid: 22545909. https://doi.org/10.5172/conu.2011.40.1.106

[4] Allen Consultancy Report. A Draft National Framework for Child and Family Health Services. Report to the Child and Wellbeing Committee. Canberra, Australia. 2009.

[5] Breach R, Jones L, Holroyd E. The Victorian maternal and child health nurse's journey to change. Australian Nursing Journal. 2012.

[6] Kruske S, Grant J. Educational preparation for maternal, child and family health nurses in Australia. International Nursing Review. 2012; 59(2): 200-207. PMid: 22591091. https://doi.org/10.1111/j 1466-7657.2011.00968.x

[7] Department of Education and Early Childhood Development (DEECD). Maternal and Child Health Service: Key Ages and Stages Framework. Melbourne: State Government of Victoria. 2009.

[8] Shonkoff JP, Boyce WT, McEwen BS. Neuroscience, molecular biology, and the childhood roots of health disparities. JAMA: the journal of the American Medical Association. 2009; 301(21): 2252-2259. PMid: 19491187. https://doi.org/10.1001/jama.2009.754

[9] Edgecombe G. Seminar discussion after presentation of PhD work, Mum's the word: Exploring Early Motherhood at Royal Melbourne Institute of Technology University. 20 November 2009.

[10] Scott D. Transcript of Proceedings from the Protecting Victoria's Vulnerable Children Inquiry. Broadmeadows. 7 July 2011.

[11] Patton M. Qualitative research and evaluation methods, $3 \mathrm{rd}$. edn. London: Thousand Oaks: Sage; 2002.

[12] Sandelowski M. Whatever happened to qualitative description? Research in Nursing \& Health. 2000; 23(4): 334-340. https : //doi.org/10.1002/1098-240X (200008) 23:4<334: : AID-NUR9>3 . 0. CO;2-G

[13] Maxwell JA. Designing a qualitative study. Handbook of applied social research methods. London: Sage Publications; 2006.
[14] Dey I. Qualitative data analysis: A user-friendly guide for social scientists. New York: Routledge; 2003.

[15] Morse JM, Field PA. Qualitative research methods for health professionals: London: SAGE Publications, Incorporated; 1995.

[16] Bazeley P. Qualitative data analysis with NVivo. London: Sage Publications Limited; 2007.

[17] Richards T, Richards L. The way ahead in qualitative computing. Journal of Modern applied statistical methods. 2003; 2(1): 16-26. https ://doi.org/10.22237/jmasm/1051747440

[18] Council of Australian Government Productivity Commission. Early Childhood Development Workforce Draft Report. Commonwealth of Australia Publishing. 2011.

[19] Happell B. Psychiatric nursing in Victoria, Australia: a profession in crisis. Journal of Psychiatric and Mental Health Nursing. 1997; 4(6): 417-422. https://doi.org/10.1046/j.1365-285 $0.1997 .00039 . \mathrm{x}$

[20] Happell B. Appreciating history: The Australian experience of direct-entry mental health nursing education in universities. International Journal of Mental Health Nursing. 2009; 18(1): 35-41. PMid: 19125785. https://doi.org/10.1111/j.1447-0349.2008.0 0565. $\mathrm{x}$

[21] Clinton M, Hazelton M. Scoping mental health nursing education. Australian and New Zealand Journal of Mental Health Nursing. 2000; 9(1): 2-10. PMid: 11271010. PMid: 11271010. https : //doi.org/10.1046/j.1440-0979.2000.00155.x

[22] Schmied V. 'Taking a risk': Child and Family Health Nurses working in integrated and collaborative service models. The Australian Association of Maternal, Child and Family Health Nurses Connections conference: Refereed paper from the 5th Biennial National conference. Canberra. 2013.

[23] Reiger K, Keleher H. Managing professionals: The emerging leadership role of Victorian Maternal and Child Health coordinators. International Journal of Nursing Practice. 2003; 10: 58-63. PMid: 15056343. https://doi.org/10.1111/j.1440-172X.2003.0 $0464 . x$

[24] O'Connor B. The Kennett Years: Scorched Earth or Creative Destruction? Paper presented at Joint AFS \& Labour History Society Conference. Melbourne, Australia. 2000. Available from: http: //www . fabian.org.au/947.asp/

[25] Chaska NL. The nursing profession: tomorrow and beyond. London: Sage Publications, Inc. 2001. PMid: 11211387. 